\title{
A Review of Undergraduate Athletic Training Program Entrance Requirements.
}

\author{
Christopher D. Brown \\ University of Florida, cdbrown7@ufl.edu \\ Kelly Potteiger \\ Northern Illinois University, kpotteiger@niu.edu \\ Kimberly Keeley \\ Slippery Rock University, kimberly.keeley@sru.edu \\ Andrew Lundgren \\ North Park University, alundgren@northpark.edu \\ Shannon David \\ North Dakota State University--Fargo, shannon.david@ndsu.edu
}

Follow this and additional works at: https://nsuworks.nova.edu/ijahsp

Part of the Medicine and Health Sciences Commons

\section{Recommended Citation}

Brown CD, Potteiger K, Keeley K, Lundgren A, David S. A Review of Undergraduate Athletic Training Program Entrance Requirements.. The Internet Journal of Allied Health Sciences and Practice. 2017 Jan 01;15(1), Article 4.

This Manuscript is brought to you for free and open access by the College of Health Care Sciences at NSUWorks. It has been accepted for inclusion in Internet Journal of Allied Health Sciences and Practice by an authorized editor of NSUWorks. For more information, please contact nsuworks@nova.edu. 


\title{
A Review of Undergraduate Athletic Training Program Entrance Requirements.
}

\begin{abstract}
Purpose: Athletic Training (AT) education is undergoing a major change with the transition to the professional Master's degree. This evolution provides opportunity for faculty to reassess programmatic requirements. Admissions criteria is the first benchmark set for students and may predict future success. Currently, there is no evidence describing common AT entrance requirements. Objective(s): To determine current practices in AT admissions, establish best practices for developing admissions criteria, and discuss the potential impact of the transition to professional master's degree on the admissions process.
\end{abstract}

Methods: Design: Cross-Sectional Study. Setting(s): Web-based survey in the fall of 2014. Participant(s): 361 undergraduate program directors received the survey; 117 (32.4\%) responded. Intervention(s): The survey consisted of 28 questions: 15 demographics questions and 13 questions relating to: Academic structure (1 question), Program admissions procedures (5 questions), and Selection Process (7 questions). Main Outcome Measure(s): Descriptive statistics were calculated for each variable.

Results: There were 117 responses, representing all 10 NATA districts. Ninety-seven percent $(n=114)$ use a secondary admission process. Additionally, the majority of programs ( $n=94,89.5 \%)$ reported using a combination of GPA data when making admissions decisions (i.e. major GPA and overall GPA). Seventytwo percent $(n=84)$ of programs require clinical experience hours (mean $47.64 \pm 33.68$ ) prior to admission. Personal attributes were assessed through the use of interviews, essays, and other written documents.

Conclusions: There are many factors that may affect a program's outcome. However, it all begins with the individual program's admission process. To strengthen the program's quality, faculty members must review their current admission criteria to ensure each requirement is purposeful, relevant, and non-discriminatory.

\section{Author Bio(s)}

Christopher Brown PhD, ATC, CSCS is a Clinical Assistant Professor at the University of Florida. He is also an Athletic Trainer in the state of Florida.

Kelly Potteiger PhD, ATC is an Associate Professor at Northern Illinois University. She is also an Athletic Trainer in the state of Illinois.

Kimberly Keeley PhD, ATC is an Assistant Professor at Slippery Rock University. She is also an Athletic Trainer in the state of Pennsylvania.

Andrew Lundgren MEd, ATC, CSCS is an Associate Professor at North Park University. He is also an Athletic Trainer in the state of Illinois.

Shannon David PhD, ATC, PES is an Assistant Professor at North Dakota State University. She is also an Athletic Trainer in the state of North Dakota.

\section{Acknowledgements}

The authors would like to acknowledge and thank Malissa Martin, Linda Platt-Meyer, and Paula Turocy for their support during this project. 


\title{
IJAHSP \\ The Internet Journal of Allied Health Sciences and Practice
}

Dedicated to allied health professional practice and education

Vol. 15 No. 1 ISSN 1540-580X

\section{A Review of Undergraduate Athletic Training Program Entrance Requirements}

\author{
Christopher Brown PhD, ATC, CSCS 1 \\ Kelly Potteiger $\mathrm{PhD}, \mathrm{ATC}^{2}$ \\ Kimberly Keeley PhD, ATC ${ }^{3}$ \\ Andrew Lundgren MEd, ATC, CSCS $^{4}$ \\ Shannon David PhD, ATC, PES 5 \\ 1. University of Florida \\ 2. Northern Illinois University \\ 3. Slippery Rock University \\ 4. North Park University \\ 5. North Dakota State University \\ United States
}

\begin{abstract}
Purpose: Athletic Training (AT) education is undergoing a major change with the transition to the professional Master's degree. This evolution provides opportunity for faculty to reassess programmatic requirements. Admissions criteria is the first benchmark set for students and may predict future success. Currently, there is no evidence describing common AT entrance requirements. Objective(s): To determine current practices in AT admissions, establish best practices for developing admissions criteria, and discuss the potential impact of the transition to professional master's degree on the admissions process. Methods: This is a cross-sectional study design via a Web-based survey in the fall of 2014. Three hundred, sixty-one (361) undergraduate program directors received the survey; $117(32.4 \%)$ responded. The survey consisted of 28 questions: 15 demographics questions and 13 questions relating to academic structure (1 question), program admissions procedures ( 5 questions), and selection process (7 questions). Descriptive statistics were calculated for each variable. Results: There were 117 responses, representing all 10 NATA districts. Ninety-seven percent $(n=114)$ use a secondary admission process. Additionally, the majority of programs $(n=94$, $89.5 \%$ ) reported using a combination of GPA data when making admissions decisions (i.e. major GPA and overall GPA). Seventytwo percent $(n=84)$ of programs require clinical experience hours (mean $47.64 \pm 33.68)$ prior to admission. Personal attributes were assessed through the use of interviews, essays, and other written documents. Conclusions: There are many factors that may affect a program's outcome. However, it all begins with the individual program's admission process. To strengthen the program's quality, faculty members must review their current admission criteria to ensure each requirement is purposeful, relevant, and nondiscriminatory.
\end{abstract}

\section{Background}

To become a certified athletic trainer (AT), the candidate must graduate from an undergraduate or graduate athletic training program accredited by the Commission on Accreditation of Athletic Training Education (CAATE). The candidate must also successfully pass the Board of Certification (BOC) examination. The BOC exam is the benchmark used to protect the public by ensuring the candidate possesses all the necessary skills for credentialing as an entry-level athletic trainer. ${ }^{1}$ Beginning in 2012 , the CAATE Standards stipulate all accredited Athletic Training Programs (ATP) must maintain a 3-year aggregate BOC first-time pass rate at or above $70 \%$; failure to do so could jeopardize the program's accreditation status. ${ }^{2}$

The emphasis on outcome-based education is not new. ${ }^{3}$ Long embedded in the secondary school setting, the Council for Higher Education Accreditation (CHEA) began recommending member institutions use student outcome and assessment practices to ensure the academic quality of their respective programs in 2001. ${ }^{4} \mathrm{CHEA}$ is a national advocate and institutional voice for selfregulation of academic quality. This organization's membership includes over 3000 degree-granting colleges and universities and 
recognizes an additional 60 institutional and programmatic accrediting organizations. ${ }^{5}$ The CAATE achieved CHEA recognition in 2014. ${ }^{6}$ According to the CAATE, this recognition "is an affirmation of CAATE's commitment to upholding quality assurance standards, and a testament to the high quality of education in CAATE accredited programs."6 A primary difference between CHEA's standards for academic quality and that of the CAATE is CHEA does not prescribe how specific outcomes are met. Instead, CHEA provides member institutions the autonomy to determine their individual benchmarks for quality.

Prospective students and their parents want to ensure their investment in education is adequate preparation for future employment. Once a prospective athletic training student decides upon a program, he or she may need to gain admittance through a secondary, or competitive, admissions process. Elements of the admissions process may include previous academic success (i.e., high school GPA and/or prerequisite GPA), scores on standardized tests (i.e., ACT, SAT, GRE), specialized tests (i.e., Allied Health Professions Aptitude Test or AT-specific entrance exams), personal interviews, recommendations, essays, accruing observational hours, and demonstration of basic clinical/taping skills. AT programs maintain the autonomy to develop their own admission criteria but share a common goal to ensure the admission process identifies both the top candidates as well as candidates who possess the attributes needed for success.

In May 2015, the Athletic Training Strategic Alliance announced their intentions to transition the professional degree to the master's level. ${ }^{7}$ This move mirrors the trend of other healthcare professions (i.e. physical therapy, physician assistants) who prepare students for professional practice at the graduate level. The transition of the entry-level degree from the undergraduate to graduate level is intended to better position the profession of athletic trainers among other providers in the healthcare arena. ${ }^{7,8}$ However, the evidence to support this move is not well documented by existing research.7

This transition of the degree requirement allows programs to reevaluate their current practices in the effort to determine how to best prepare students for success. Multiple studies attempted to predict success in AT by examining select student attributes ${ }^{9-14}$ Among them, grade point average (science, major, and overall) is documented as the strongest predictor of success. . $^{9-11} \mathrm{~A}$ correlation between the number of clinical hours accrued and success is also identified. ${ }^{13}$ However, clinical hours were tabulated over the duration of the curriculum and therefore not appropriate as a criterion for admission to an AT program at the undergraduate level. There is no evidence for the efficacy of letters of recommendation, essays, observational hours, or basic clinical/taping skills. At the time of publication, there is no published research available investigating why these criterion measures are included in the application process or an explanation of the characteristics they are attempting to measure. One theory is during the rapid transition from internship to accredited program in the early 2000s, many of the professional programs used a "cookie-cutter" approach to replicate the competitive admissions processes of previously accredited sister programs (i.e. physical therapy or physician assistant) as a way to ensure they would meet the standards needed for accreditation. ${ }^{15}$

Considering the upcoming transition to the professional master's programs and high stakes surrounding student success for the professional programs, now is the time to explore how specific elements of the application process may help identify candidates best suited for success in the profession. ${ }^{7}$ Therefore, the purpose of this study is to explore current undergraduate AT admissions criteria across the country to determine differences and trends. In particular, what admission criteria do undergraduate AT programs currently utilize, and of these, which are most prevalent?

\section{Methods}

A cross-sectional survey design was used to identify undergraduate AT programs' current admissions criteria. The survey was developed in the spring of 2014 by the research team. The survey was developed using a table of specifications to ensure congruency of the instrument with the research question and reviewed for content and construct validity by a panel of three content experts as recommended by Creswell. ${ }^{17,18}$ Content experts were selected based on their experience as athletic training educators as well as expertise in athletic training pedagogy and survey development. As a result of the content experts' feedback, the survey was revised and reorganized to better reflect the content area and research question before initial distribution. On recommendation from the content experts, trustworthiness was also established through peer review. The disseminated survey included a total of 28 (15 demographic) items including a combination of closed-ended (i.e., multiple choice, select all that apply) and open-ended questions. The other 13 questions related to academic structure (1 question), program admissions procedures (5 questions), and selection process (7 questions).

Once a psychometrically sound instrument was developed, the survey was emailed to 361 professional undergraduate AT program directors in the fall of 2014. Following the initial email invitation, reminder emails were sent two weeks apart to all program directors. The survey remained open for a total of 6 weeks. The University of Southern Mississippi Institutional Review Board approved the study, and all participants acknowledged informed consent before entering into the survey.

(C) The Internet Journal of Allied Health Sciences and Practice, 2017 
All data analyses were completed using PASW (version 18.0; SPSS Inc., Chicago, IL). Descriptive statistics were employed to calculate mean, standard deviation, frequencies, and percentages.

\section{Results}

This instrument was sent to 361 pre-professional undergraduate athletic training programs during Fall of 2014. There were 117 responses, with representation from all 10 NATA districts (Table 1) for a total response rate of $32.4 \%$.

Table 1: Number of Programs by NATA District $(n=117)$

\begin{tabular}{|c|c|c|}
\hline District & Number & Percentage \\
\hline 1 & 6 & 5.1 \\
\hline 2 & 12 & 10.3 \\
\hline 3 & 18 & 15.4 \\
\hline 4 & 32 & 27.4 \\
\hline 5 & 20 & 17.1 \\
\hline 6 & 4 & 3.4 \\
\hline 7 & 4 & 3.4 \\
\hline 8 & 5 & 4.3 \\
\hline 9 & 13 & 11.1 \\
\hline 10 & 3 & 2.6 \\
\hline
\end{tabular}

Table 2 summarizes the program descriptive data including the number of full-time faculty, the number of adjunct faculty, the average number of student applications, and average cohort size.

Table 2: Program Demographics ( $\mathrm{n}=117)$

\begin{tabular}{|l|c|c|c|c|}
\hline Item & Minimum & Maximum & Mean & SD \\
\hline Number of full-time faculty & 1 & 8 & 2.6 & 1.1 \\
\hline Number of adjunct faculty & 1 & 11 & 4.7 & 3.2 \\
\hline Average number of applications & 0 & 165 & 23.1 & 20.1 \\
\hline Average cohort size & 4 & 40 & 13.1 & 6.9 \\
\hline
\end{tabular}

Of the 117 programs reporting their admissions criteria, $97.4 \%(n=114)$ used a secondary admission process and did not directly admit students from high school. Programs reported utilizing a points system $(n=71,60.7 \%)$, criterion list $(n=21,17.9 \%)$, perception of the admissions committee $(n=15,12.8 \%)$, and other $(n=10,8.5 \%)$ when making admission decisions. Table 3 displays the personnel who interpret the admissions criteria.

Table 3: Admissions Personnel $(n=117)$

\begin{tabular}{|l|c|c|}
\hline & Number & Percentage $^{\mathbf{a}}$ \\
\hline Program director & 116 & 99.1 \\
\hline Clinical education Coordinator & 106 & 90.6 \\
\hline Other AT faculty members & 66 & 56.4 \\
\hline Clinical staff & 48 & 41 \\
\hline Non-AT administration & 24 & 20.5 \\
\hline Students & 17 & 14.5 \\
\hline Adjunct faculty members & 16 & 13.7 \\
\hline Graduate assistants & 16 & 13.7 \\
\hline Other & 4 & 3.4 \\
\hline Medical doctor & 2 & 1.7 \\
\hline aResults are not cumulative & & \\
\hline
\end{tabular}




\section{Grade Point Average}

All programs reported using a 4.0 GPA scale. The majority of programs ( $n=94,89.5 \%)$ reported using a combination of GPA data when making admissions decisions (i.e. major GPA and overall GPA). When reviewing the GPA requirement used as entrance criteria, a total of $92(78.6 \%)$ programs used the major GPA to determine entrance criteria, while $85(72.6 \%)$ used overall GPA and $22(18.8 \%)$ programs used other (i.e. science) GPA data for entrance criteria. Programs using multiple GPA requirements (overall, major, science, etc.) for program admission were counted once.

\section{Prerequisite courses}

A total of $90(76.9 \%)$ schools reported pre-requisite classes are required as part of their admissions process. Below is the list of classes by category that were cited as prerequisites to admissions into the AT program (Table 4). The digit listed represents the number of programs citing a course (or in some instances, more than one course), in that category. Examples of courses in the "other" category include Introduction to Exercise Science, Strength Training, and Research Methods.

Table: 4: Prerequisite Courses $(n=90)$

\begin{tabular}{|l|c|c|}
\hline \multicolumn{1}{|c|}{ Category } & Number $^{\text {a }}$ & Percentage $^{\text {b }}$ \\
\hline Intro to athletic training & 79 & 87.8 \\
\hline Anatomy and physiology & 76 & 84.4 \\
\hline Emergency medicine and first aid & 61 & 67.8 \\
\hline Practical skill/clinical/lab & 34 & 37.8 \\
\hline Prevention \& Care & 29 & 32.2 \\
\hline Biology & 27 & 30.0 \\
\hline Kinesiology & 15 & 16.7 \\
\hline Health & 14 & 15.6 \\
\hline Math & 14 & 15.6 \\
\hline Psychology & 14 & 15.6 \\
\hline Chemistry & 13 & 14.4 \\
\hline Taping/bracing & 10 & 11.1 \\
\hline Nutrition & 9 & 10.0 \\
\hline Physics & 8 & 8.9 \\
\hline English & 6 & 6.7 \\
\hline Evaluation/assessment & 3 & 3.3 \\
\hline Modalities & 3 & 3.3 \\
\hline Other & 17 & 18.9 \\
\hline
\end{tabular}

aNumber of programs citing a course (in some instances, more than one course), in a category bResults not cumulative

\section{Clinical Hours Differences}

Seventy-two percent $(n=84)$ of programs require either observational hours or another type of directed clinical experience prior to admission to the professional program. The mean number of required hours was $47.64 \pm 33.68$. Figure 1 displays the observation hour frequencies in 25 -hour allotments. 


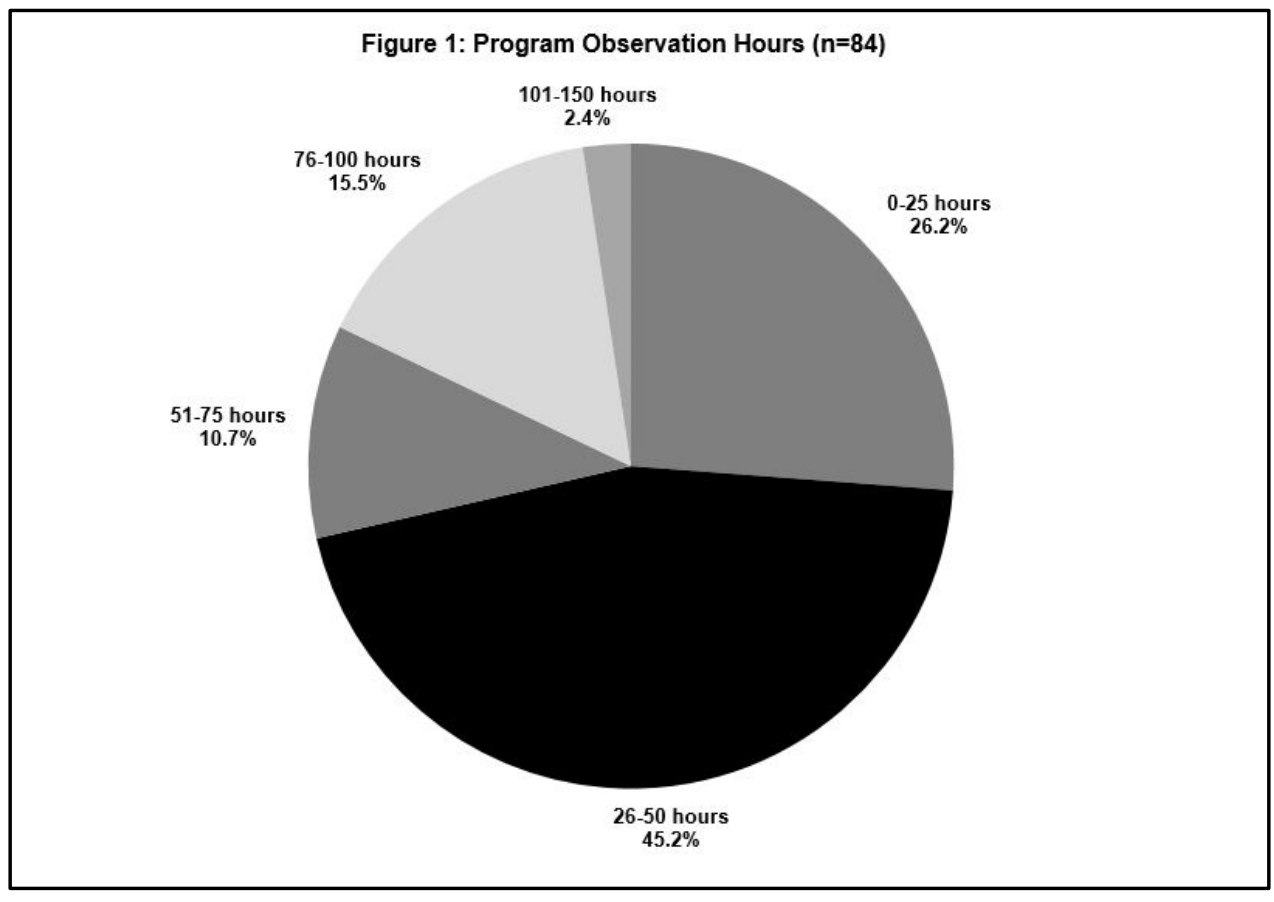

\section{Personal Attributes}

Programs report measuring a candidate's personal attributes through the use of interviews, essays, and other written documents (i.e. resumes, cover letters, and/or letters of recommendation). Half of programs who use interviews as part of their admission process $(n=45)$ report using a combination of both structured (prepared question list) and open-ended (non-prepared question list) interview guides, $42.2 \%$ of programs use only structured questions $(n=38)$ while $7.8 \%(n=7)$ report using only an open-ended format. Table 5 displays the personnel who participate in each program's interview process.

Table 5: Personnel in Interview Process $(n=90)$

\begin{tabular}{|l|c|c|}
\hline & Number & Percentage $^{\mathrm{a}}$ \\
\hline Program director & 89 & 98.9 \\
\hline Clinical education coordinator & 87 & 96.7 \\
\hline Other AT faculty members & 56 & 62.2 \\
\hline Clinical staff & 53 & 58.9 \\
\hline Students & 34 & 37.8 \\
\hline Graduate assistants & 24 & 26.7 \\
\hline Non-AT administration & 22 & 24.4 \\
\hline Adjunct faculty members & 18 & 20 \\
\hline Other & 4 & 4.4 \\
\hline Medical doctor & 2 & 2.2 \\
\hline aResults not cumulative & & \\
\hline
\end{tabular}

Programs report the aim of the formal interview is to assist in identifying specific candidate attributes as indicated in Figure 2. Programs report the aim of the written documents (essays, resumes, cover letters) is to assist in identifying specific candidate attributes as indicated in Figures 3 and 4. 
Figure 2: Attributes Assessed by Interview ( $n=78$ )
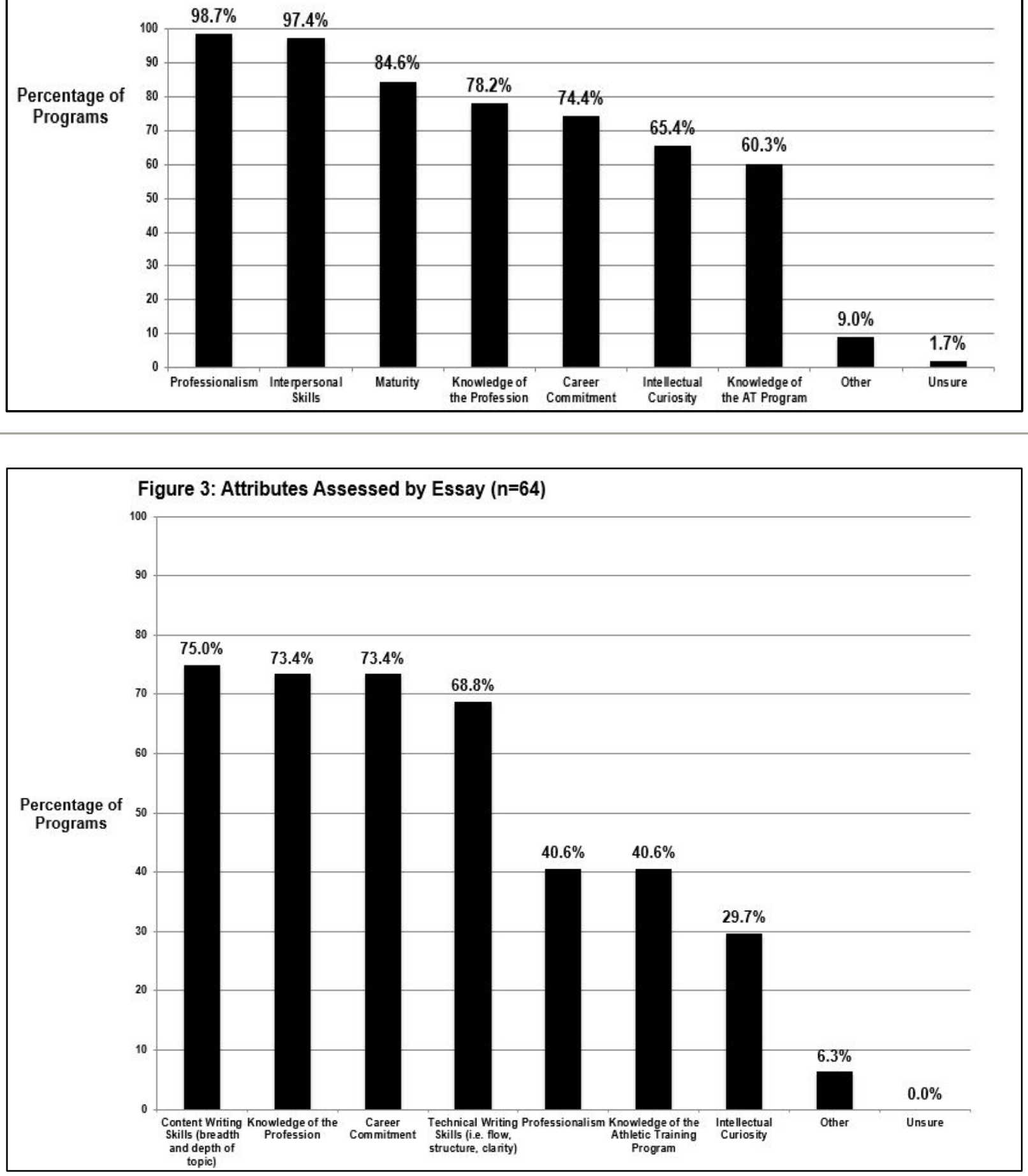


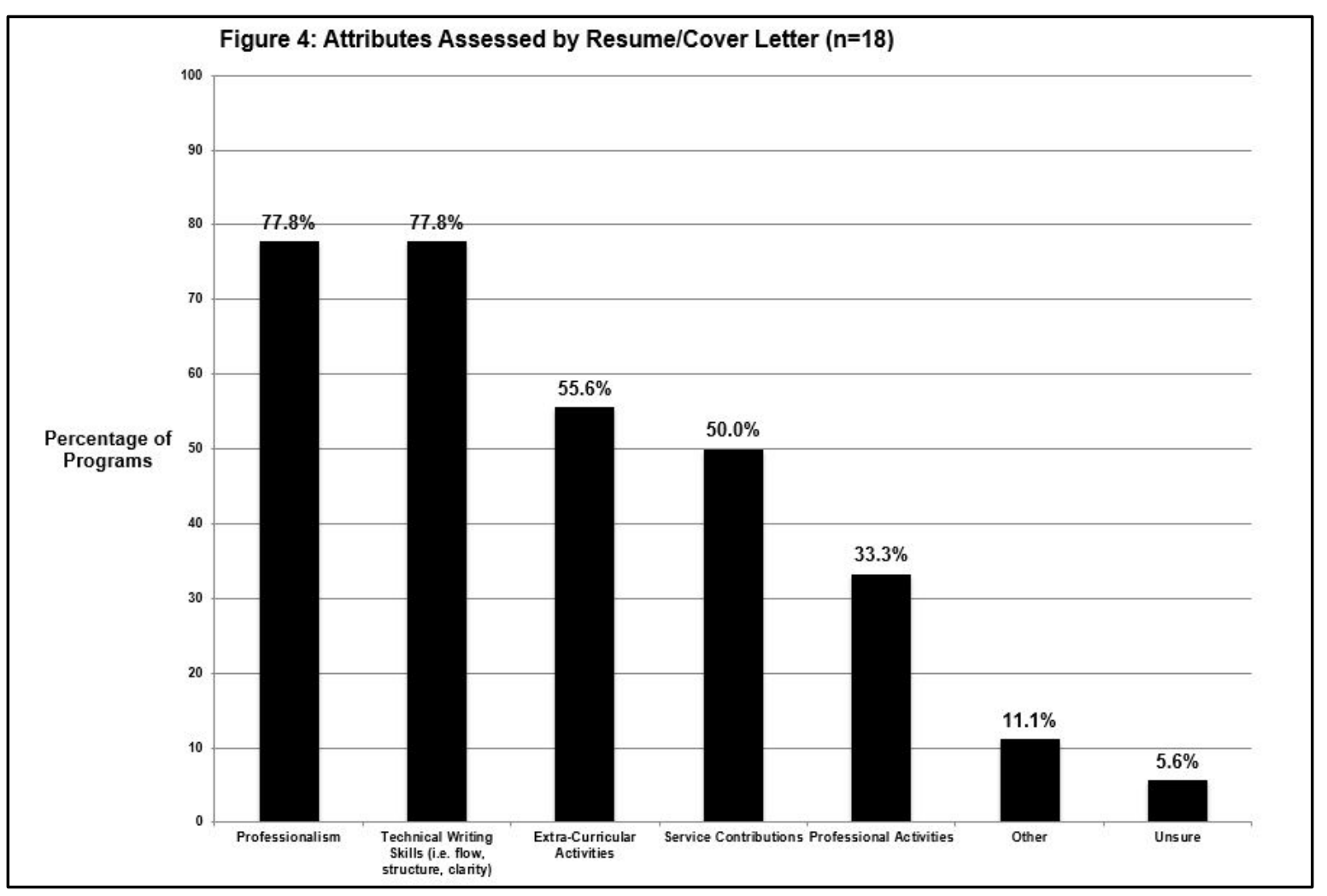

\section{Discussion}

In previous literature, various measures of GPA were correlated with student success, both programmatically and on the BOC exam. ${ }^{10,13,14}$ However, these findings may no longer be relevant since the BOC exam format changed significantly since these results were published. Minimum published GPA may be misleading because program faculty could regularly admit students above the minimum GPA, which would create inflation between the published minimum GPA and the actual GPA of the students admitted to the program. To better utilize the GPA requirement, faculty at individual programs should determine the minimum GPA need to effectively screen for student success. In addition, programs may consider publishing the average GPA of their previous cohorts to increase transparency for applicants.

This determination should assist in increasing the number of quality applicants by reducing the number of unqualified applicants. With the transition of the professional degree to the master's level, GPA may become an even more important determinant of student success. For example, for students who currently apply after one to two semesters, an overall GPA of 2.0 may not signify a lack of potential. However, application to graduate school with a cumulative GPA of 2.0 may suggest more substantial issues attaining academic success. Programs that regularly rely on unqualified candidates to maintain student numbers may experience a decline of qualified students capable of academic success at the graduate level. Many other graduate level allied health programs have explored predictors to gauge a candidate's potential for success in their field. These include nursing, physical therapy, occupational therapy, and physician assistant. ${ }^{20-25}$ The most common variables investigated included Graduate Requisite Examination and undergraduate grade point average, and lesser used variables included interviews, letters of recommendation, and written work. ${ }^{20,21,23,24}$ None of the studies were able to accurately predict future success, but a limiting factor could be the lack of definition of the term "success."

Another factor that influences program admissions is standardized testing. In the current study, only $11.1 \%$ of programs reported using standardized testing (ACT; SAT; etc.) as part of their admission criteria. Three programs out of $117(2.6 \%)$ reported using a direct admissions process to accept students directly from high school. With the transition to the professional level master's degree, more programs will elect to use a direct admissions process. Therefore, we believe the use of standardized testing, as an admissions requirement, will also increase. Many graduate schools currently utilize the Graduate Requisite Exam (GRE) across the U.S. for admissions decisions. While the literature suggests the GRE is predictive of success at the graduate level, it is also linked to favor those from certain socio-economic classes, races, and ethnicities. ${ }^{27-29}$ The Educational Testing Service, who administers the GRE, cautions the exam should not be used as a sole determinant in admission decisions. ${ }^{30}$ An increased reliance 
on standardized testing during program admissions may contribute to a lack of diversity within the AT profession. The cultural and ethnic backgrounds of healthcare professionals should reflect the diversity of the population served. ${ }^{31} \mathrm{An}$ increase in the diversity of healthcare providers is recommended to improve access to and quality care of minority patients, enhance educational experiences for healthcare students, and promote relevant research needed to change health care policy. ${ }^{32}$ The March 2016 membership report by the National Athletic Trainers' Association's (NATA) Ethics and Diversity Committee reported 46,570 total members. Approximately $81 \%$ ( $n=37,617,80.77 \%$ ) of those identify as white (not of Hispanic origin). Graduate student membership mirrors the professional membership with over two-thirds $(n=444,64.62 \%)$ also reported as white (not of Hispanic origin). ${ }^{33}$ Therefore, athletic training educators should question whether their program should rely on a determinant that may decrease the already low number of minority candidates. Programs should evaluate their admission procedures in the effort to avoid unintentional discriminatory practices.

Another potentially influential item in the ethnic diversity of the profession is a measurement of candidate personality traits via written essay, formal interviews, or both. In this study, 78 programs $(66.7 \%)$ included a written essay as part of their application process while 94 programs (80.3\%) reported utilizing interviews to help make the decision. Both practices are subjective in nature, may unfairly impact individual candidates and provide little relevance on future success in either academic or clinical practice. ${ }^{34,35}$ Written essays may negatively affect minority students because of linguistic errors. ${ }^{36}$ While formal interviews may be influenced by a variety of factors including appearance, sequencing effect (whether or not a candidate is preceded by several highly or lowly rated candidates), as well as a host of other potential discriminatory biases such as gender, age, race, and physical or mental disability characteristics. ${ }^{35}$ Programs can seek to minimize discrimination in the evaluation process by ensuring the admissions review panel is culturally diverse. Including a reviewer trained in the assessment of ESL (English as a second language) students may help to minimize discrimination on written essays. The literature suggests psychometric tests assist to determine objectively personality characteristics and abilities in medical school candidates. ${ }^{31}$ Athletic training educators should examine the psychometric tests common in the medical community to determine the applicability of like exams in the AT admissions process.

Clinical hour differences (Figure 1) were another requirement with a large variance between programs. While the majority of programs required between 26 to 50 clinical or observation hours for entry, two programs required between 101 and 150 hours. Previous research found no correlation between clinical hours and success. ${ }^{13}$ A large number of clinical hours are a tradition for many athletic trainers, and cultural change is slow. Therefore, it is possible this requirement is a holdover from previous admission policies. Additionally, faculty may not realize fewer clinical hours are an option, or the large number may be ingrained in faculty and students and is not considered for change.

A method AT programs can use to increase efficiency as they make the transition to the graduate degree is using a centralized admissions process. Although fairly new, athletic training programs may decide to utilize the Athletic Training Centralized Application System (ATCAS) available through CAATE. ${ }^{26}$ Comparable to the centralized application systems used for physical therapy, occupational therapy, physician assistant studies, and medical schools, the ATCAS is designed to aid students applying to multiple programs. The ATCAS allows students to upload information one time and share with their selected programs. This process allows for better efficiency of both the students and program faculty by decreasing the time spent handling paperwork from multiple sources.

Some educators may choose to transition their professional program to the graduate level using a $3+2$ curricular model. This type of design combines a three-year pre-professional undergraduate program with a two-year professional graduate program. Students and parents may find the accelerated time frame financially attractive in light of rising tuition costs. However, there may also be shortcomings to this type of program. First, students may not decide on athletic training as a major until well into their college career or some may choose first to attend a two-year college for the academic and financial opportunities provided. In addition, students who lack foundational knowledge may struggle with the pace of an accelerated program. Athletic training educators using a 3+2 design should carefully examine their admission criteria to ensure students' foundational knowledge while avoiding unintentional discrimination as described above. In some cases, programs may wish to establish a "bridge" program to assist students who are transferring from a two-year program or lack foundational knowledge.

No matter the curricular design, programs should reflect upon the quality of accepted students as well as the rigor and applicability of entry requirements in light of the CAATE requirement to maintain a 3-year, first time, aggregate pass rate of $70 \%{ }^{19}$ Based on our findings, we included the following recommendations for improving the AT program admission process:

1. Programs should actively review their application process to determine whether each requirement (i.e. GPA, clinical observation hours, pre-requisite courses) is beneficial to the program as well as a valuable use of the students'/faculty members' time and resources. This may be especially important during a professional program's transition from an undergraduate to a graduate program.

() The Internet Journal of Allied Health Sciences and Practice, 2017 
2. Programs should focus time and resources on the entry requirements they believe will lead to overall program improvement rather than which entry requirements will predict BOC pass rate.

3. To decrease the internal time and resources necessary during the application process, programs should consider using the standardized application process.

4. When using processes to assess students' personal attributes (i.e. essay, interview), programs should include a diverse panel to prevent unconscious bias.

\section{Limitations}

While we attempted to survey $100 \%$ of undergraduate AT programs, we only received data from $32.4 \%$ of programs. A low participation rate may limit the generalizability of our data.

\section{Directions of Future Research}

Future research should be directed at potential influencers of 1 st-time BOC pass rate including admissions criteria, faculty experience, faculty education, student clinical education, student personality intrinsic information, and within program GPA. This research should focus on programs at the graduate level because of the transition to a professional master's degree. Another avenue of future research is to examine the impact of admissions processes on the ethnic and racial diversity within the profession.

In addition, as an incidental finding to this study, we discovered a seemingly wide variance in the number of full-time faculty per program. Eleven programs (9.4\%) reported only having one full-time faculty member. Seven of these programs (63.6\%) were from District 5 (IA, KS, MO, NE, OK, ND, SD). Given the high demands on program faculty, it seems hard to imagine a full-time faculty of one is sufficient to deliver quality education in today's ever-changing educational landscape. A faculty of one is also problematic as it violates CAATE Standard 30 which mandates a 1.0 full-time equivalent (FTE) faculty member aside from the Program Director. ${ }^{19} \mathrm{It}$ is possible these programs incorrectly reported their FTE numbers or they could be utilizing dual appointed faculty positions to meet the standard. It is also possible programs could have been between hires for an open position. Future research should focus on the number and type of full-time faculty per program needed for student success.

\section{Conclusion}

The transition to a professional master's degree program, along with revisions of the professional standards, are attempts to raise the bar not only in AT education but the profession as a whole. As a result, educational programs are forced to become more accountable for student success. There are many factors that may affect a program's outcome. However, it all begins with the individual program's admission process. To strengthen the program's quality, faculty members must review their current admission criteria to ensure each requirement is purposeful, relevant, and non-discriminatory.

\section{References}

1. Athletic Training Education Overview. 2014. http://www.nata.org/sites/default/files/AT-EducationOverview.pdf. Accessed November 15, 2016.

2. Communication Regarding Outcome Standards. Insight: a publication from the Commission on Accreditation of Athletic Training. 2014. https://caate.net/wp-content/uploads/2014/05/CAATE-Insight-Newsletter-Spring-2014_VF.pdf. Accessed November 15, 2016.

3. Harden RM, Crosby JR. AMEE guide no. 14: Outcomes-based education: part 1- an introduction to outcomes-based education. Medical Teacher. 1999;21(1):7-14.[PMID: 21281173]

4. $\quad$ Ewell PT. Accreditation and Student Learning Outcomes: A Proposed Point of Departure. Washington, DC: Council of Higher Education Accreditation. http://www.chea.org/award/StudentLearningOutcomes2001.pdf. 2001. Accessed November 15, 2016.

5. $\quad$ Council for Higher Education Accreditation. 2015. http://www.chea.org. November 15, 2016.

6. CAATE Achieves CHEA Recognition. 2014. http://caate.net/caate-achieves-chea-recognition/. Accessed November 15, 2016.

7. Professional Degree Standards. Insight: a publication from the Commission on Accreditation of Athletic Training. Summer 2015. http://caate.net/wp-content/uploads/2015/06/CAATE-Summer-2015-Insight-Newsletter.pdf. Accessed November 15, 2016.

8. Professional education in athletic training: an examination of the professional degree. National Athletic Trainers' Association Executive Committee for Education. 2013.http://www.nata.org/sites/default/files/The_Professional_Degree_in Athletic_Training.pdf. Accessed November 15, 2016.

9. Erickson MA, Martin M. Contributors to initial success on the National Athletic Trainers' Association Board of Certification examination as perceived by candidate sponsors: a delphi study. J Athl Train. 2000;35(2):134-8.[PMID: 16558621]

(C) The Internet Journal of Allied Health Sciences and Practice, 2017 
10. Harrelson GL, Gallaspy JB, Knight HV, Leaver-Dunn D. Predictors of success on the NATABOC certification examination. J Athl Train. 1997;32(4):323-7.[PMID: 16558467]

11. Harrelson GL, Leaver-Dunn D, Wright KE. An assessment of learning styles among undergraduate athletic training students. J Athl Train. 1998;33(1):50-3.[PMID: 16558485]

12. Leaver-Dunn D, Harrelson GL, Martin M, Wyatt T. Critical-thinking predisposition among undergraduate athletic training students. J Athl Train. 2002;37(4(supplement)):S147-51.[PMID: 12937536]

13. Middlemas DA, Manning JM, Gazzillo LM, Young J. Predicting performance on the national athletic trainers' association board of certification examination from grade point average and number of clinical hours. J Athl Train. 2001;36(2):13640.[PMID: 12937453]

14. Platt LS, Turocy PS, McGlumphy BE. Preadmission criteria as predictors of academic success in entry-level athletic training and other allied health educational programs. J Athl Train. 2001;36(2):141-4.[PMID: 12937454]

15. Potteiger K, Brown C, Kahanov L. Altering the athletic training curriculum: a unique perspective on learning over time. Athl Train Educ J. 2012;7(2):60-9.

16. Timeline 2000-2009. http://www.bocatc.org/timeline/76-history/415-2000-2009. Accessed November 15, 2016.

17. Turocy PS. Survey research in athletic training: the scientific method development and implementation. $J$ Athl Train. 2002;37(4 suppl):S174-9.[PMID: 12937541]

18. Creswell JW. Research Design: Qualitative, Quantitative and Mixed Methods Approaches, 2e. Thousand Oaks, CA: Sage Publications; 2003.

19. CAATE Standards for Accreditation of Educational Programs for the Professional Preparation of the Athletic Trainer 2012 Professional Standards. Austin, TX: Commission on Accreditation of Athletic Training Education 2012.

20. Rhodes ML, Bullough B, Fulton J. The Graduate Record Examination as an admission requirement for the graduate nursing program. J Prof Nurse. 1994;10(5):289-96.[PMID: 7995885]

21. Newton SE, Moore G. Undergraduate grade point average and Graduate Record Examination scores: the experience of one graduate nursing program. Nurs Educ Perspect. 2007;28(6):327-31.[PMID: 18240739]

22. Zipp GP, Ruscingno G, Olson V. Admission variables and academic success in the first year of the professional phase in a doctor of physical therapy program. J Allied Health. 2010;39(3):138-42.[PMID: 21174017]

23. Levine SB, Knecht HG, Eisen RG. Selection of physical therapy students: interview methods and academic predictors. J Allied Health. 1986;15(2):143-151.[PMID: 3721994]

24. Kirchner GL, Holm MB. Prediction of academic and clinical performance of occupational therapy students in an entrylevel master's program. Am J Occup Ther. 1997;51(9).[PMID: 9311434]

25. Hayes SH, Fiebert IM, Carroll SR, Margill RN. Predictors of academic success in physical therapy programs: is there a difference between traditional and nontraditional students? J Phys Therapy Educ. 1997;11(1):10-6.

26. Apply Now: ATCAS Central. http://caate.net/apply-nowl. Accessed November 15, 2016.

27. Kuncel NR, Wee S, Serafin L, Hezlett SH. The validity of the Graduate Record Examination for master's and doctoral programs: a meta-analytic investigation. Educ Psychol Meas. 2010;70(2):340-52.

28. Pennock-Roman M. Background characteristics and future plans of high-scoring GRE and general test examinees. Princeton, NJ: Exxon Education Foundation 1994.

29. Scott RR, Shaw ME. Black and white performance in graduate school and policy implications for using GRE scores in admission. J Negro Educ. 1985;54(1):14-23.

30. For Test Takers. 2015. http://www.ets.org/gre. Accessed November 15, 2016.

31. Lumsden MA, Bore M, Millar K, Jack R, Powis D. Assessment of personal qualities in relation to admission to medical school. Med Educ. 2005;39:258-65.[PMID: 15733161]

32. Sullivan LW. Missing persons: minorities in the health professions. Sullivan Commission on Diversity in the Healthcare Workforce;2004.

33. Ethnicity Demographic Data. 2016. https://www.nata.org/sites/defaultffiles/ethnicity-demographics.pdf. Accessed September 26, 2016.

34. Prideaux D, Roberts C, Eva K, et al. Assessment for selection for the health care professions and specialty training: consensus statement and recommendations from the Ottawa 2010 conference. Med Tech. 2011;33(3):215-23.[PMID: 21345061]

35. Goho J, Blackman A. The effectiveness of academic admission interviews: an exploratory meta-analysis. Med Tech. 2006;28(4):335-40.[PMID: 16807172]

36. Johnson D, VanBrackle J. Linguistic discrimination in writing assessment: how raters react to African American 'errors', ESL errors, and standard English errors on a state-mandate written exam. Assess Writ. 2012;17(1):35-54.

37. Program Outcomes. http://caate.net/program-outcomes/ - Pass-Rate. Accessed November 15, 2016. 